\title{
Ottmar Ette: vida en la literatura y literatura en la vida
}

Josu Landa

a relación de la literatura con la vida es fuerte y profunda. Las obras literarias surgen de la vida y responden a una raigal necesidad humana de enriquecer a ésta y hacerla más llevadera por medio de ellas. Producir formas poéticas -en la acepción más amplia, griega, del adjetivo- es parte muy importante de lo que hace la voluntad de vivir. Ya en el Banquete, Diotima alecciona a Sócrates en el sentido de que "los que son fecundos según el alma", en contraposición a quienes lo son "según el cuerpo", conciben y dan a la luz "el conocimiento y cualquier otra virtud, de las que precisamente son procreadores todos los poetas y cuantos artistas se dice que son inventores". ${ }^{1}$ Generar discursos con sentido estético es una de las maneras más ricas e intensas de vivir y de garantizar la continuidad de la vida; también de dar cuenta de la existencia de los mortales en este mundo, con todo lo que tiene de gozoso, doloroso, paradójico, contradictorio, enigmático...

Ottmar Ette nos recuerda todo esto, en "Teoría literaria como saber de vida" (Literaturwissenchaft als Lebenswissenschaft) ${ }^{2}$ su fecundo "Escrito programático" (Programmschrift), destinado a proponer nuevos rumbos al ejercicio de la filología y los estudios literarios, a propósito de la celebración de 2007 como "Año de las humanidades".

El tono del texto de Ette viene marcado, en cierta medida, por el impulso crítico del joven Nietzsche de las "Consideraciones intempestivas" (unzeitgemässe Betrachtungen); concretamente, la segunda: la que versa sobre los

${ }^{1}$ Platón, "Banquete", en Diálogos, vol. III. Introd., trad. y notas de Carlos García Gual, M. Martínez Hernández y Emilio Lledó Íñigo. Madrid, Gredos, 1986, 209 a.

${ }^{2}$ Ottmar Ette, "Literaturwissenschaft als Lebenswissenschaft", en Lendemains, núm. 125. Tubinga, Gunter Narr, 2007. A la hora de emprender el presente acercamiento crítico-dialógico al escrito de Ette, se ha tenido en cuenta la primera versión del texto alemán al español, efectuada por Elisabeth Sieffer, Ute Seydel y Sergio Ugalde. 
beneficios y los perjuicios de la historia para la existencia humana. La referencia es doblemente llamativa: porque se trata de un filólogo-pensador radicalmente vitalista y porque la perspicacia de ese todavía "primer" Nietzsche se fija en aquello que, en el tiempo, en el momento y en el "clima" cultural que le toca vivir, se ha estancado y huele a rancio porque niega la vida. En contra de un saber que asume el pasado como un cadáver embalsamado y que se regodea en el polvo de "nimiedades [Quisquilien] bibliográficas"; en contra, pues, de una actitud que en escritos posteriores caracterizará como "egipcíaca", afanada en momificar todo lo vivo y vital, Nietzsche aboga, desde temprano, por una ciencia histórico-filológica que se comprometa con una cultura entendida como "una physis nueva y mejorada", como una "unificación de vida, pensamiento, ilusión y voluntad". ${ }^{3}$ Sin coincidir necesariamente con el contenido preciso de esa aspiración nietzscheana, Ette asume la actitud ante el saber que le sirve de fondo, en la medida en que su propio planteamiento surge de la necesidad de responder la pregunta por "el provecho y los inconvenientes de los saberes literarios [Literaturwissenschaft(en)] para la vida". ${ }^{4}$

Ese "movimiento intempestivo", que a su manera impulsa Ottmar Ette, no pierde de vista las legítimas reservas que puede implicar una vinculación entre literatura y vida, en el terreno de los saberes literarios. Ette está consciente de que tal operación teórica no puede desdeñar la especificidad y la consustancial complejidad de los estudios literarios, ese "jardín del saber", en el presente. En concordancia con esa restricción epistémica, Ette expone con claridad lo que no es ni pretende alcanzar su propuesta teórica. Como el propio autor explica, sus reflexiones no pretenden desentenderse de la índole compleja de las creaciones, las teorías y los estudios literarios. De ahí que rechace, con toda pertinencia, la vieja idea de la literatura entendida como reflejo de la sociedad, debida a un marxismo vulgar o demasiado lastrado de positivismo. De ahí, también, que tome una clara distancia frente al crudo afán positivista de ceñirse a la investigación de las fuentes. Análogos reparos críticos muestra ante las llamadas "filosofías de la vida", hoy tan venidas a menos; al mismo tiempo que evita toda estéril confrontación con las ciencias naturales, en congruencia con un desacato claro de la tesis de "las dos culturas" de Charles Percey Snow. Esas prevenciones ante referencias epistemológicas otrora prácticamente insoslayables, de cara a la comprensión y examen de los siempre dinámicos campos

3 "So entschleiert sich ihm der griechische Begriff der Cultur [...] der Begriff der Cultur als einer neuen und verbesserten Physis, ohne Innen und Aussen, ohne Verstellung und Convention, der Cultur als einer Einhelligkeit zwischen Leben, Denken, Scheinen und Wollen" (Friedrich Nietzsche, "Unzeitgemässe Betrachtungen II" ("Vom Nutzen und Nachteil der Historie für das Leben"), en Sämliche Werke, vol. I. Ed. crítica de Giorgio Colli y Mazzino Montinari. Múnich, Walter de Gruyter, 1999, p. 334).

${ }^{4}$ O. Ette, op. cit., p. 8. 
literarios, no obstan, sin embargo, para seguir asignándoles a los contextos históricos, sociales y culturales la máxima importancia. Lo que, en definitiva, marca el rumbo futuro de la filología y todas las opciones teórico-discursivas afines es su disposición y capacidad de dar cuenta del modo específico como opera la complejidad en el mundo de la literatura: la manera concreta en que se muestran las dimensiones "inter y transmediales" (inter-und transmedialen), así como inter y transculturales, en el ámbito de la escritura. ${ }^{5}$

En lo que tiene de diagnóstico sobre la situación de la literatura contemporánea y los metadiscursos que se ocupan de ella, el texto de Ottmar Ette destaca la paradoja de un creciente interés de importantes sectores de las sociedades contemporáneas por lo que genéricamente llama "las filologías" y el desdén que hacia ellas muestran las instancias que definen las políticas relativas a las ciencias y a los procesos de cohesión social. En palabras del propio autor, "desde hace mucho tiempo a las filologías se les ha concedido una posición marginal en los discursos públicos y en los de las políticas científicas". "Esta observación coloca la perspectiva de Ottmar Ette en el doble plano de la reflexión sobre las bases teóricas de una continuidad renovada de los saberes literarios, por un lado, y el de sus implicaciones en el terreno de la definición y la gestión de los programas para su impulso social futuro, por el otro. Aun cuando, como debe ser, Ette otorga más importancia a los aspectos teoréticos y epistemológicos aquí implicados, no ignora la relevancia de cierto sentido práctico e incluso de una considerable dosis de pragmatismo, con miras a reasentar a la literatura y los estudios literarios en el espacio público y, más precisamente, en la trama de proyectos, dispositivos, recursos, estrategias y normas por medio de las cuales aquéllos puedan cumplir su función cultural.

La propuesta de Ottmar Ette no se sustenta, pues, ni en una nostalgia idílica de una Edad de Oro de la filología ni en un criticismo vacuo ni en un simple utilitarismo ajeno a compromisos culturales profundos. En su caso, la pregunta de corte "intempestivo" sobre los beneficios y los perjuicios que acarrean a la vida la literatura y los saberes que la circundan no da pie a tratados perí bíos, más o menos serios o pintorescos, como en la Grecia antigua; tampoco un recetario de opciones metódicas, con el consabido fardo de categorías y tesis que sólo esperan la "aplicación" - lo que sea que signifique esto en las humanidades- de hábiles momificadores de los diversos avatares de la buena escritura. Si el joven Nietzsche miraba a la Antigüedad clásica, para curarse de las miserias de su tiempo, Ette - al contrario- nos ofrece una amplia serie de iniciativas complementarias, con miras a una refundación de la teoría y la crítica literarias, conforme a las coordenadas de la nueva modernidad que

\footnotetext{
${ }^{5}$ Cf. ibid., pp. 8-9.

${ }^{6}$ Ibid., p. 9.
} 
se ha venido gestando, a instancias de la actual "globalización acelerada" - la expresión se la he leído y escuchado al propio Ette- no sólo en el terreno de la economía y la cultura, sino en el de los saberes mismos.

En concordancia con ese empeño, Ette propone "una filología orientada a las ciencias de la vida", ${ }^{7}$ una filología que asuma "a las ciencias de la literatura como ciencias de la vida". ${ }^{8}$ Esto implicaría apelar al potencial crítico de la teoría literaria para "preguntar por un concepto de vida abierto y por un saber de la vida en el sentido de un saber en la vida". 9 La premisa de la que parte la propuesta de Ette es la de que las novelas, los poemas, los dramas ofrecen "un saber vital condensado literariamente". ${ }^{10}$ Así, desde la perspectiva de Ette, la obra literaria se ofrece como un "depósito de saber vital dinámico". ${ }^{11}$ Más aún: para Ette, el texto con valor artístico opera como un "espacio vivencial", como un escenario en el que se pone de relieve un reservorio de conocimientos en torno a experiencias vitales (Erlebenswissen) que, en su condición de tales, anclan en la vida las existencias de los personajes y convierten a éstos en referencias de sentido, de cara a los estudios literarios, en la medida en que también pueden descubrir un saber-sobre-el-vivir (Überlebenswissen) y un saber-de-convivencia (Zusammenlebenswissen) humano. ${ }^{12}$ De ahí la pertinencia de una filología entendida como una especie de bio-filo-logía, como el análisis de la escritura conforme a lo que ésta expresa acerca del vivir y el morir de los agonistas sobre los que versa; también con la mira puesta, por extensión, en la época en que la historia de esas vidas y muertes tiene lugar. Se trata, pues, de leer las trayectorias trazadas, en su peculiar paso por este mundo, $v$.g., por don Quijote, madame Bovary, monsieur Goriot, Père Ubu o Santiago Nasar, en las páginas labradas por Cervantes, Flaubert, Balzac, Jarry y García Márquez. ${ }^{13}$

En último término, lo antedicho comporta una reflexión sobre el concepto de "vida", desde la especificidad epistémica de la filología; es decir: un acercamiento a la existencia humana al modo de "una tentativa estratégica que incida, tanto en el contenido como en los métodos" 14 de las ciencias relativas a la literatura. Ette está claramente consciente, pues, de que su tesis en torno a un reencauzamiento de la filología reclama una honda revisión del lugar que ésta ha venido ocupando en el campo epistemológico. De entrada, es frecuente

\footnotetext{
${ }^{7}$ Ibid., p. 26.

${ }^{8}$ Ibid., p. 10.

${ }^{9}$ Ibid., p. 11.

${ }^{10}$ Ibid., p. 26.

${ }^{11}$ Ibid., p. 28.

${ }^{12}$ Cf. ibid., p. 32.

${ }^{13}$ Cf. ibid., p. 26.

${ }^{14}$ Ibid., p. 10.
} 
que recurra con preferencia al plural "filologías" (Philologien) ${ }^{15}$ y, más aún, a un término de mayor extensión semántica, como el de Literaturwissenschaft (ciencia o saber concerniente a la literatura), que también se puede usar en plural, cuando el caso lo permite o requiere. En esto, el texto de Ette que aquí se examina viene a ser la síntesis de un programa teórico que tiene su antecedente más firme en los dos volúmenes de su Überlebenswissen, publicados en 2004 y $2005 .^{16}$

Situada en el entorno de ese saber (Wissen) que retematiza el vivir para comprometerse de manera inédita con la literatura, la idea de "vida" que aflora en el "escrito programático" de Ottmar Ette responde a "una recuperación del concepto de vida fundamentada en las teorías culturales y literarias", así como a la "aceptación del saber sobre el vivir" que ello comporta, en el entendido de que así podría agregarse "una dimensión cultural imprescindible en la comprensión científica de las ciencias biológicas en tanto ciencias de la vida". ${ }^{17}$ De ese modo, Ette se propone una meta que hoy puede lucir titánica: superar "la reducción de bíos [el vocablo griego que nombra a la vida como existencia personal y no como simple despliegue de una potencia natural] a un concepto de las ciencias naturales, en el que no se incluye la dimensión cultural". ${ }^{18}$ El llamado de atención y aun la denuncia sobre esa extraña maniobra epistemológica reductora -todo un acto de poder- ya se habían hecho con anterioridad. Recuérdese, tan sólo a título de ejemplo, la observación que al respecto hacía el todavía joven Heidegger (1925) - es decir, mucho antes que Giorgio Agamben, citado a este propósito por Ette- ${ }^{19}$ en el contexto de una crítica letal al psicologismo: "bíos [...] significa para los griegos lo mismo que existencia humana o ser personal”, por lo que una auténtica biología vendría a parecerse más a una psicología, mientras que lo que hoy y desde hace tanto tiempo se llama "biología" debería denominarse, en rigor, "zoología", ciencia de la zoé, entendida esta voz como "vida vegetal y animal". ${ }^{20}$

15 Ibid., p. 11.

${ }^{16}$ O. Ette, Überlebenswissen. Die Aufgabe der Philologie, Berlín, Kadmos, 2004, y Zwischen WeltenSchreiben. Literaturen ohne festen Wohnsitz (Überlebenswissen II). Berlín, Kadmos, 2005.

${ }^{17}$ O. Ette, "Literaturwissenschaft als Lebenswissenschaft", en op. cit., pp. 30-31.

${ }^{18}$ Ibid., p. 10.

${ }^{19}$ Cf. ibid., p. 16.

${ }^{20}$ Cf. Martin Heidegger, Lógica. La pregunta por la verdad. Trad. de Joaquín Alberto Ciria. Madrid, Alianza, 2004, p. 38. Por su valor ilustrativo, conviene citar el pasaje heideggeriano in extenso: "Psicología, en el sentido del griego antiguo, significa aproximadamente [...] biología tomada en sentido literal: la ciencia de la vida. Más estrictamente tendríamos que decir zoología, en tanto que la vida, tal como la considera la antigua psicología, tiene el significado de zoé. Zoé en sentido aristotélico es el ser vegetal y animal; zoé, vida en el sentido actual de lo biológico. Mientras que bíos, si 
Pero, si todo intento de revertir esa reducción consumada de lo biológico a lo estrictamente natural se antoja difícil en grado sumo, no por ello carece de pertinencia. De manera lenta pero firme, se ha venido consolidando la idea de que las representaciones de la naturaleza, incluyendo las que sirven de base a las llamadas ciencias naturales, son una construcción de índole cultural. La antigua disyunción entre un orden de la physis y una realidad cultural, completamente ajena y superpuesta a aquél, ha venido dando paso a una visión más compleja de los nexos entre un ámbito y otro. Esto es lo que confiere coherencia al planteamiento de Ottmar Ette, en el sentido de optar por un concepto de "vida" sustentado en el discurso literario, de modo tal que las Life Sciences "se conviertan en ciencias de la vida en sentido pleno" y dejen de ser disciplinas orientadas a dar cuenta de un mero impulso vital natural. ${ }^{21}$

Ahora bien, a la hora de formular su tesis, como lo advierte él mismo, Ottmar Ette no se mueve por la intención de ofrecer un presunto "saber superior sobre la vida", a partir del arte y la literatura. ${ }^{22}$ Lejos de tan vana pretensión, el filólogo alemán aboga con persistencia por el diálogo y la cooperación de las ciencias literarias con las bio-ciencias, en términos de una "estrategia doble", en virtud de la cual se acceda a "conocimientos básicos de las ciencias culturales y humanísticas", a la par de que se proceda a la "obtención transdisciplinaria de una comprensión de la vida, así como de las ciencias de la vida”. ${ }^{23}$ Desde esa perspectiva, lo que estaría en juego, de cara al futuro de las filologías, sería la posibilidad de que éstas se constituyeran en "ciencias de la vida", ${ }^{24}$ en la medida en que contribuyeran al impulso de "una concepción no reduccionista de la vida", con base en la "creación de redes [...] entre las más diversas ciencias". ${ }^{25}$ Ottmar Ette piensa, pues, en "crear estructuras dialógicas, más allá de la separación de 'las dos culturas'", ${ }^{26}$ como dio en denominar el ya mencionado Charles Percy Snow, a la dicotomía disciplinaria entre ciencias y humanidades;

lo interpretamos al modo totalmente extremo, significa para los griegos lo mismo que existencia humana o ser personal, tal como se aprecia por ejemplo en el término 'biografía'. En griego, por ejemplo, en la ética aristotélica, bíos designa una posibilidad de la existencia: bíos theoretikós: existencia del hombre científico. De esta manera, precisamente estos dos términos están invertidos. Biología significa la ciencia de la existencia del hombre o de sus fundamentos, es decir, la pregunta por los fundamentos de la ética. En tanto que ciencia del bíos, la psicologia pertenece a la ética; en tanto que ciencia de la zoé, a la física".

${ }^{21}$ O. Ette, "Literaturwissenschaft als Lebenswissenschaft", en op. cit., p. 22.

${ }^{22}$ Ibid., p. 31.

${ }^{23}$ Ibid., passim, pp. 10-11.

${ }^{24}$ Ibid., p. 32.

${ }^{25}$ Cf. ibid., p. 11.

${ }^{26}$ Ibid., p. 31. 
se trata, pues, de procurar una relación entre ambos campos epistemológicos, en términos de "complementariedad de enfoques y metodologías". ${ }^{27}$

La propuesta de Ottmar Ette no es una suerte de proyecto idílico, algo como una pasión gratuita o quijotesca, afanada en superar la crisis epistemológica que aqueja a las humanidades, a instancias, sobre todo, del modelo empíricopositivista y tecnicista de ciencia hegemónico y de su redoblado impulso, por mor de la nueva globalización acelerada. Muy al contrario, será difícil hallar hoy en día un programa más realista y mejor fundado que el del filólogo alemán, ante la ya prolongada impasse teórica y aun política -no olvidemos que, como el propio Ette apunta, todo esto tiene consecuencias en una amplia gama de dispositivos de financiación y normatividad, atingentes a la educación, la investigación, el desarrollo de actividades culturales y procesos afines- que afecta a todo el campo humanístico. A fin de cuentas, la tesis de Ette se cimienta en un dato comprobable:

[...] la literatura no sólo es capaz de simular formas normativas de la praxis vivencial, sino que también puede ofrecerlas de manera performativa y, así, apegadas a la vida y "vivibles"; ello, debido a que la literatura contiene un saber acerca de los límites de la validez de los saberes en una cultura o sociedad dadas. A su vez, este saber de la literatura implica un conocimiento en torno a los límites y la validez del saber sobre el vivir y sobre el convivir, que se condensa en la literatura misma. [...] ese saber experiencial, adquirido con los medios de la literatura, tiene un valor inestimable, justo por su polisemia y su indeterminación en la fase actual de la globalización. ${ }^{28}$

La solidez de la tesis de Ottmar Ette radica justo allí donde parecería estribar su presunta debilidad óntico-epistémica: en esa apertura ("indeterminación" en un sentido lato) de lo real y hacia lo real, que comportan las realidades que articula el discurso literario. Se ha visto siempre como algo poco menos que incuestionable la seguridad, certeza y aun "exactitud" de las ciencias naturales, en contraste con la subjetividad y marcada falibilidad inherentes a los saberes humanísticos. Al margen de lo artificioso de esa disyunción y de que se puede argumentar, con sobradas bases, sobre la subjetividad y falencia igualmente consustanciales a las llamadas "ciencias duras", para discurrir en abono a la propuesta de Ette, será suficiente con traer a colación los límites de la idea de "vida" sobre la que se cimientan los actuales saberes "biológicos". La primera aseveración estipulable, a este respecto, es que éstos no

${ }^{27}$ Ibid., p. 32.

${ }^{28}$ Ibid., pp. 31-32. El subrayado es del autor. 
tienen un acceso más profundo a la realidad de la vida que la literatura. La biología del presente descansa en una ignorancia ontológica de lo que es la vida; sus representaciones acerca de ésta no son cualitativamente superiores a las expresiones que la literatura ofrece acerca sobre las más diversas dimensiones de la existencia.

El vasto dominio de las ciencias biológicas ha desarrollado, en los últimos tiempos, al fragor de los avances de la física, un complejo y abigarrado sistema de procedimientos metódicos, instrumentos de micro y nanoscopía, variables medibles y observables, definiciones operacionales, categorías, descripciones de objetos, procesos y regularidades adscritos al campo de la vida natural. Es admirable la profundidad y amplitud alcanzadas por la biofísica y la fisiología molecular, los estudios genómicos, la manipulación genética y otras expresiones de los más avanzados conocimientos y adelantos tecnológicos relativos a los organismos vivos. Pero, por mucho que los científicos ahonden en la escala micro y nanométrica, por mucho, asimismo, que incrementen hasta cotas que nunca se habían franqueado su comprensión sistémica, global, del reino animal y vegetal, no es epistemológicamente lícito ignorar que sus saberes y procedimientos de generación de sentido responden a un paradigma científico históricamente determinado y, por ende, inscrito en los límites de validación que ese mismo orden del sentido impone. El modelo hegemónico de ciencia es una construcción cultural, sin duda, dotada de una poderosa base legitimadora, como son sus referentes empíricos y sus proyecciones en la efectividad técnica; pero la realidad humana, cuya dimensión natural sería necio desdeñar, rebasa con creces esos límites. Por lo demás, se supone que todos los afanes de las actuales ciencias y tecnologías de avanzada apuntan a redimir al género humano de sus males y limitaciones, por una vía distinta a la que siempre han procurado transitar las diversas expresiones de la cultura humanística. En el supuesto de que, en esa carrera en pos de la omnipotencia, las "ciencias duras" del presente lograran tan magno propósito, ello carecería por completo de sentido, si no fuera interpretable por una humanidad dotada de las bases humanísticas (en un contexto histórico, cultural, comunitario... específico) aptas para una exégesis epistemológica y éticamente consistente. Lo cual confirma la insensatez de todo intento por evitar la (re)integración de los saberes científicos-naturalistas de la vida con las hondas y rigurosas intuiciones que sobre el mundo-de-la-vida aportan los más variados discursos de teoría y de literatura.

Con todo y sus innegables avances, la biofísica del presente no puede blasonar de haber dado con una definición universalmente válida de "vida". Para poder avanzar en el acceso a sus objetos de estudio, debe conformarse, al igual que todas las ciencias biológicas y naturales, con definiciones operacionales, es decir: enunciados formulados con base en referencias empíricamente observa- 
bles y convencionalmente estipuladas, que faciliten el acopio de información sobre las variables sometidas a investigación. Según, por caso, el doctor Nasif Nahle Sabag, "desde el enfoque de la biofísica, vida es un estado de la energía de algunos sistemas cuasi-estables, que determina una serie de intervalos que demoran la dispersión espontánea de la energía interna de esos sistemas hacia más microestados potenciales". ${ }^{29}$ Ésta es una definición operacional de vida, presentada aquí con carácter meramente ilustrativo. El investigador que la estipula se ve, a su vez, en la necesidad de elucidar, a la manera de nuevas definiciones operacionales, una serie de nociones incluidas en la precitada definición, como "energía", "energía interna", "sistema cuasi-estable", "demorar", "dispersión espontánea”, "microestados potenciales” y otras que van surgiendo en el momento en que se proponen dichas elucidaciones y que sería excesivo, además de ocioso, registrar aquí. A fin de cuentas, desde la actual vanguardia de las ciencias biológicas de nuestro tiempo, lo único que puede decirse con sentido y fundamento acerca de la vida es que se trata de la propiedad común a los seres vivos, los cuales se definen operacionalmente como sistemas complejos formados por células, dotadas de una estructura molecular y en cuyo seno -es decir, en los límites demarcados por sus membranas-acontecen determinadas reacciones químicas. Esos sistemas siempre proceden de otros, se autosostienen, se reproducen y dejan de existir. En conjunto e individualmente, los seres vivos entablan un intercambio necesario y permanente de energía con su entorno, lo cual les permite efectuar las mencionadas reacciones químicas y perdurar hasta que permanezca su estructura celular. Más allá de los méritos y utilidad de esta representación de lo vivo, la ciencia no puede explicar cómo las bases físico-materiales de los objetos inertes -quarks, leptones, bosones, protones, neutrones, electrones, núcleos atómicos, átomos, moléculas, energía cuántica, etcétera- lo son, también, de los organismos vivientes. La biología, en cualesquiera de sus ramas, sigue sin poder desentrañar la enigmática verdad de qué materias análogas pueden derivar en seres dotados de vida o en subsistencias carentes de ella.

Está claro que es difícil, si no imposible, definir la vida, si por tal se entiende dar razón de qué es ésta, cuál es su principio o fundamento, cuál es su sentido... No es fácil acertar con el género al que se adscribe el fenómeno de la vida ni con su diferencia específica; no damos con el definiens universal que englobe el hecho del vivir y las definiciones operacionales que estipulan las ciencias biológicas apenas dan cuenta, como se ha visto, del comportamiento de ciertas variables y de la articulación de ciertas estructuras de relaciones. Pero esto no significa que estemos en el grado cero del saber acerca de lo

${ }^{29}$ Nasif Nahle S., Exobiología, Biology Cabinet. New Braunfels, TX, 2006. [Obtenido el 30 de mayo de 2009 en http://biocab.org/Exobiología.html.] 
que es la vida. En un célebre pasaje de sus Confesiones (libro XI, cap. XIV), san Agustín reconocía que, mientras nadie le preguntara qué es el tiempo sabía de qué se trataba; pero, si alguien se lo preguntara, no. Algo semejante ocurre con el vivir: es la realidad más común y familiar; tenemos un fuerte y persistente nexo intuitivo con el vivir y, en muy buena medida, sabemos de qué hablamos cuando nos referimos a él, aunque -al menos por el momentonos resulte inaccesible su radical verdad y, por ello, nos esté prácticamente vedado formular el enunciado veritativo, definitorio y definitivo, del caso. Esa dilatada y honda zona de saber intuido, aunque no definido con precisión, sobre la vida es la que parece constituir el fondo de realidad en que se cimienta la literatura; por lo mismo, parece ser también la principal referencia óntica de la propuesta de Ottmar Ette. En virtud de ese conocimiento inmediato del vivir de que dispone el ser humano, los discursos humanísticos -tanto los de cariz teórico como los de índole estética- ofrecen una valiosa y nutrida gama de representaciones sobre el despliegue en el tiempo de una inagotable y multidimensional voluntad de existir, de perseverar en el ser, como le gustaría decir a Spinoza. De ese modo, el pensamiento y la literatura han impulsado, cada cual por su lado o de manera conjunta, un proceso milenario de producción de sentido acerca de la vida, que hoy en día también está en capacidad de absorber positivamente las aportaciones que, al respecto y a su modo, prodiguen las ciencias biológicas.

En el caso concreto de la literatura, el problema ontológico y epistemológico a encarar, a propósito de lo que se viene planteando en estas líneas, es el de la relación de la escritura de vocación estética con el sentido. En la medida en que el texto de intención creativa -siempre una conjunción de algún grado de narratividad con transignificación poética- remite a un saber intuitivo de la vida, muchas veces incomparablemente rico y profundo, termina operando como un modo específico de tratado asistemático perí bíos. Así, la obra literaria bien estructurada y suficientemente dotada de vitalidad humana y artística se ofrece como un escenario en el que se expone un mundo-de-la-vida alterno, por lo que los referentes de sentido operantes en los mundos natural y cultural factuales son análogos a los que fundan las realidades y las vidas literarias. En ese hábitat discursivo, los personajes literarios ostentan una entidad estructuralmente afín a la de los sujetos de carne y hueso que pueblan el orden "real", por lo que aquéllos, en tanto que habitantes del mundo-de-la-representación poscartesiano, se sostienen sobre el mismo fondo ontológico que éstos. Algo semejante cabe decir de los actos que realizan esos agonistas, de las situaciones en que se desenvuelven... en suma: de todo lo que supone el mundo escrito -más que descrito- por los más diversos avatares de la literatura. La novela moderna, por ejemplo, más que simular la vida cotidiana construye un universo ad hoc y unas vidas paralelas a las que registra cualesquiera demografía, historia o 
sociología. Don Quijote, en la segunda parte de la obra maestra cervantina, o ciertas "personas" inventadas por Unamuno o Pirandello son seres vivos que, por ello mismo, aspiran a las mismas libertades que cualquier mortal y se rebelan contra las potestades del narrador. El discurso literario se presenta, así, por una parte, como un espacio analógico de integración de bíos y zoé, como mímesis de la unidad de la existencia y, por otra, como el registro de wittgensteinianas "formas de vida", razón por la que puede ser asumido como una fuente de saber en torno al sentido de esa existencia, sobre todo, en lo que atañe a lo más específicamente humano.

La idea central de Ottmar Ette -si está siendo bien captada en este análisis- consiste precisamente en llamar la atención de la crítica, los estudios literarios, las filologías, sobre esta realidad, de manera que la literatura pueda ser asumida conforme a una necesaria coextensividad y coimplicación, en igualdad de condiciones, de los saberes que ella ofrece acerca de la vida y los que provienen del discurso científico. Es lo que se desprende de un pasaje como éste: “...la literatura se puede concebir como un medio de acumulación interactivo y transformante de saber sobre el vivir, que simula, se apropia, proyecta y condensa modelos de conducción de vida y con ello recurre a los discursos científicos y a los más distintos segmentos de saber" ${ }^{30}$ En este punto, Ette echa mano de referencias que parten de la tematización de la vida y de su conversión en objeto de estudio, tanto en el terreno de las Life Sciences como en el de la filosofía (Agamben, Foucault, Habermas...) y en el de las reflexiones más específicamente literarias de Bajtin, Barthes, Iser, Lotman y otros, lo cual confiere a su escrito programático la densidad propia de un texto a la altura del más exigente debate contemporáneo sobre el asunto que verdaderamente se dirime aquí: el de los nexos entre representación, vida y verdad, en el contexto concreto de los saberes literarios.

En un plano que rebasa con fortuna las lindes de lo óntico-epistémico, Ottmar Ette parece dar una vuelta de tuerca más, al asumir la condición humana conforme a la vaga, fronteriza, pero a la vez intensa concretud de la topografía del umbral, ese modo del límite. Ette echa mano, a este respecto, de la idea expuesta por Giorgio Agamben, en el sentido de que el hombre es "el umbral central", por sobre el cual transitan "las corrientes de lo humano y de lo inhumano, de subjetivación y desubjetivación, de la llegada al lenguaje del ser vivo y de la vivificación del $\log o s " .{ }^{31}$ Este carácter de nudo o limen de todo lo sublimemente cultural, propio del hombre histórico, puede ser postulado no sólo como plataforma antropológica de la posibilidad misma de los intercambios de contenidos cognitivos que comporta la transdisciplinariedad

\footnotetext{
${ }^{30}$ O. Ette, "Literaturwissenschaft als Lebenswissenschaft", en op. cit., p. 13.

${ }^{31}$ G. Agamben apud ibid., p. 16.
} 
por la que aboga Ette, sino también como la base de una conjunción fáctica de las experiencias, representaciones, saberes que sustentan la vida de toda persona, con independencia de su naturaleza, sentido o valor veritativo. El simple hecho de ser en unas coordenadas históricas (una cultura, un orden social, un "mundo") confiere a la persona el carácter de punto de absorción de una extensa escala de saberes sobre y para la vida, al margen de su estatuto epistemológico. El caso de la joven poeta cubana Juana Borrero ilustra de manera por demás expresiva, dada su radicalidad, ese destino. Como apunta Ette, al escribir a su amante, con su propia sangre, en enero de 1896, la carta en la que conmina a aquél a optar por "tu Juana" o por la patria por cuya independencia combate, la poeta crea una "presencia verdaderamente corporal en el papel". ${ }^{2}$ Pero esa anécdota extrema sólo plasma, con vivaz plasticidad trágica, lo que es propio de todo ser humano en sociedad: ser en el logos y por el logos, entendido el decisivo vocablo griego en toda su dimensión ontopoética y antropogenética.

Al menos en América Latina, el escrito programático de Ottmar Ette todavía afronta los escollos propios de los momentos iniciales de una recepción que se antoja lenta, aunque efectiva. Sus ideas capitales empiezan a ser asimiladas y a suscitar las reflexiones del caso, con el consiguiente debate vivo y plural, transdisciplinario, que pretende su autor y es de esperarse de un texto signado por una evidente fecundidad y riqueza teorética. La traducción y publicación de los dos tomos de su Überlebenswissen catalizaría, sin duda, ese proceso de inserción dialógica de las tesis de Ette en los territorios en los que se cultivan los diversos saberes relativos a la literatura. A reserva de que tan afortunado suceso acaezca algún día, el texto aquí examinado condensa con suficiencia el núcleo de las ideas de Ette acerca del papel y el sentido de las filologías en el presente, lo cual hace posible e impostergable el diálogo crítico acerca de ellas.

La primera observación que puede hacerse en esa dirección -aunque, por el momento, sólo sea de manera enunciativa y tentativa- es la que concierne al papel que parece conferirle Ottmar Ette a la cultura. La idea de naturaleza sobre la que se basa toda la producción de sentido conforme al modelo hegemónico de ciencia es una construcción cultural, no un en-sí ni, por lo mismo, una objetividad absoluta. Es lícito y teóricamente fecundo apelar a este dato, como contrapeso al chato naturalismo que cimienta al discurso científico sobre la vida. Sin embargo, los problemas ontológicos-epistemológicos que comporta esa disyunción entre naturalismo y culturalismo no se tratan con verdadera efectividad teórica, si la estratagema epistemológica de base, a ese respecto, se cifra en la procura de un complemento de los descubrimientos científicos

${ }^{32}$ Ibid., p. 17. 
con las proposiciones mejor fundadas provenientes del campo humanístico o filológico. Las dificultades y aporías registrables en este espinoso campo temático imponen colocarse en una perspectiva más exigente, propiamente radical: la de una nueva ontología de la physis. Si la cultura es una suerte de "segunda naturaleza", se torna obvio que remite a un fondo primordial, pero del cual sólo podemos dar razón desde las mediaciones que implica algún grado de concreción cultural. Éste es el círculo que se debe acometer, a fin de pensar en las posibilidades de un nuevo nexo entre representaciones de la vida conforme a la ciencia y teorías - "contemplaciones", "intuiciones"- del vivir según los discursos literarios. Esto puede sonar ilusorio a los cruzados del cientificismo, pero no les vendría mal reparar, por ejemplo, en que el principio de identidad - tan decisivo para todo método, es decir: "camino", con pretensión científica- aflora por primera vez, en Occidente, por entre los hexámetros teóricos-narrativos del poema ontológico de Parménides. Se trata de una tarea en verdad ingente, a cuyo cumplimiento Ottmar Ette hace aportaciones de innegable valor.

La tendencia -comprensible y, sobre todo, urgente, dadas las diversas derivas del cientificismo en las sociedades actuales- a tratar de completar la visión científica de la vida con aportaciones procedentes del ámbito de los discursos literarios puede dar pie a otro peligro: la asunción de la literatura desde una perspectiva utilitaria, particularmente, moralista. Si, como se ha visto, la escritura literaria del mundo echa sus raíces en las cifras de la existencia y, de ese modo, nos las muestra de manera más pregnante, con efectos vitales más amplios y profundos que las descripciones de las reacciones químicas de nuestras estructuras moleculares, no debe causar demasiada extrañeza que las lecturas acerca de los modos en que se despliega la articulación de bíos y zoé que es la realidad en que nos desenvolvemos alimenten, a su vez, una reducción de lo literario al plano de la utilidad moral, pedagógica, política y afines. Desde luego, el hecho de que un "saber sobre el vivir" se deslice hacia la ética no es en sí mismo objetable. Los vínculos entre ethos y escritura artística son tan complejos y fuertes como los que ya se han señalado entre naturaleza y cultura. Nada justifica una disociación total de ambos niveles o campos, siempre entrelazados; lo que tampoco obsta, por su parte, para reivindicar siempre una distinción clara entre la función estética y la ético-política de todo discurso artístico. Lo que sí es reprobable, pues, es toda reducción de lo literario a lecturas y usos pragmáticos; más aún, su sometimiento ancilar a intereses extra o antiliterarios. Desde luego, nadie más consciente de estos peligros y extravíos potenciales que Ottmar Ette. Pero en su despliegue por los dominios de la recepción, sus tesis pueden se asumidas de manera diferente a lo esperado por su autor. Ese riesgo es evidente, aunque también es cierto que nadie podría proponer hoy en día, sin serios problemas, algo como, por ejemplo, la 
estratagema de Plutarco consistente en conducir al joven hacia la filosofía, a partir de una lectura utilitaria de la poesía. ${ }^{33}$

Lo dicho se vincula, también, con otro problema por entero fecundante, en el plano de las reflexiones suscitadas por el escrito de Ottmar Ette: el de la pluralidad de efectos de la literatura. Si a algo está atento, a su manera, el filólogo alemán es al asunto de las secuelas esperables del contacto entre el lector $-\mathrm{o}$, en general, receptor- y el texto; lo demuestran las páginas dedicadas a las diversas formas de modelado del saber sobre el vivir, tanto dentro como fuera de la escritura, ${ }^{34}$ donde dialoga con autores como Iser, Lippe, Maalouf y otros de innegable categoría. Sin embargo, es obvio que, por razones teóricas, Ette se ha visto obligado a enfatizar la peculiar dimensión epistemológica de la literatura; es decir: se ha visto en la necesidad de destacar ese siempre posible efecto de la obra literaria, por sobre las demás derivaciones esperables de ésta. Es posible que los riesgos de esta operación -inevitable, dados los propósitos del texto de Ette- se vean con mayor claridad con el simple recurso a un ejemplo ilustrativo y ampliamente conocido: el equilibrio que procura Aristóteles, en su Poética, entre placer, purga ético-catártica, saber teórico y utilidad práctica. Uno de los rasgos que salta a la vista más vivamente en esa obra clásica, que hemos heredado incompleta, es su muy marcado interés por los efectos de las diversas artes literarias, a escala de la persona y/o de la comunidad. Esa misma atención meticulosa a los efectos estéticos -y también suasorios, como es lógico- se observa asimismo en su Retórica, como lo demuestra, en especial, el tratado sobre las pasiones que alberga en su seno. Esta referencia puede marcar la pauta en cuanto a que, el sentido último de la escritura con intención artística es una relación con el mundo mediada por un placer específico; todas las demás posibilidades deben girar alrededor de este eje, sin que por ello, desde luego, queden anuladas o sean desdeñables. Aunque pueda sonar unilateral o esquemático planteado de este modo, lo cierto es que antes y como fundamento de las virtualidades teóricas del texto literario, está su poder para mantener con vida al ser humano en el mundo -eso que con expresión equívoca se ha caracterizado como "consuelo metafísico"-; esto es: la literatura como fuente de vida y la existencia humana como un proceso constante de recepción literaria.

Todo esto induce, por lo demás, a una consideración de los límites de la transdisciplinariedad, como base de la relación de la teoría literaria con las ciencias biológicas. Este nivel de conexión es del todo necesario, pero deja fuera algo

${ }^{33}$ Cf. Plutarco, "Cómo debe el joven escuchar la poesía", en Obras morales y de costumbres (Moralia), vol. I. Trad., introd. y notas de Concepción Morales Otal y José García López. Madrid, Gredos, 1985, p. 158.

34 "Texinterne und textexterne Modellierungen von Lebenswissen". 
que acaso puede o debe ser su complemento o su condición de despliegue positivo: una más amplia, diversificada y profunda recepción de la literatura a escala individual y social. Si todo se reduce al plano de los intercambios teóricos, se corre el riesgo de que el discurso científico absorba y reduzca a su lógica los saberes sobre la vida que procedan de la literatura. En este contexto, no parece un propósito ilusorio aspirar a que los biólogos y científicos afines sean también grandes lectores de literatura, al mismo tiempo que los lectores, en general, y los críticos y los estudiosos de la literatura se familiaricen más con los conocimientos sobre el vida, producidos por las distintas ramas de la biología. Ello, básicamente, porque se trata de reactivar la continuidad entre literatura y vida -hoy debilitada, cuando no desvencijada-, al modo en que se registra en las sociedades de mayor dinamismo y auge cultural. Hay elementos para pensar que se debe actuar mucho más de lo que últimamente se hace en el terreno de la recepción literaria, sin que ello signifique rendir tributo acrítico a proyectos teóricos y de política cultural justamente cancelados.

Finalmente, no estará demás dar la máxima importancia a un dato socialcultural -vale decir: no constitutivo de las referencias teóricas en juego- que deberá afrontar el proyecto de Ottmar Ette: la indiferencia, para decir lo menos, que distingue al universo de las ciencias naturales, respecto de la literatura, los estudios literarios y, en general, las humanidades. Éste es un hecho plenamente conocido por el filólogo alemán, especialmente en lo que toca a sus deplorables secuelas en las políticas de financiamiento de la investigación humanística. Un entorno humano lacerado por la decadencia de las humanidades, el imperio de los medios de (in)comunicación y progresiva barbarización, la especialización desenfrenada y el culto acrítico a la eficacia técnica parece poco propicio para una reinserción de las filologías en el orden general de los saberes y, en particular, en el de los que atañen al vivir.

Uno de los méritos mayores del escrito programático de Ottmar Ette radica, justamente, en haber contribuido a remover todos estos datos, en parte, obturadores, pero en parte, también, dinamizadores, en aras de una conciencia renovada del lugar de la vida en el desenvolvimiento de la literatura y del papel de la literatura en la comprensión sintética, totalizante, de esa máxima complejidad de la existencia, que es el vivir. 